\title{
ANÁLISE DA VIABILIDADE TÉCNICA DE UTILIZAÇÃO DE RESÍDUOS DE CONSTRUÇÃO E DEMOLIÇÃO NA FABRICAÇÃO DE BLOCOS DE VEDAÇÃO
}

\author{
Technical feasibility study of the use of construction and demolition wastes in the \\ production of sealing blocks
}

\section{Leonardo Carvalho Mesquita ${ }^{1}$, Izabel Christina d'Almeida Duarte de Azevedo ${ }^{2}$, Eduardo Souza Cândido ${ }^{3}$, Gabriel Almeida Cathoud ${ }^{4}$}

Recebido em 01 de novembro de 2014; recebido para revisão em 02 de maio de 2015; aceito em 22 de agosto de 2015; disponível on-line em 09 de novembro de 2015.

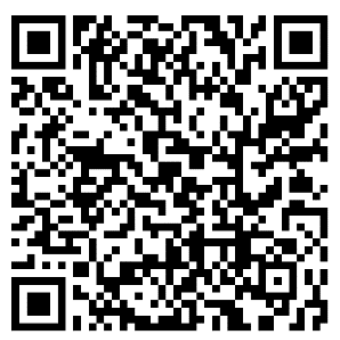

\section{PALAVRAS CHAVE:}

Resíduos de construção; Resíduos de demolição; Agregados; Blocos de vedação; Resíduos Sólidos Urbanos; Concreto. KEYWORDS:

Construction and demolition residues; Aggregates for construction; Sealing blocks; Solid waste; Concrete.

RESUMO: No Brasil, os resíduos de construção civil e demolição (RCD) chegam a atingir $60 \%$ da massa total de resíduos sólidos urbanos (RSU) produzidos, com geração per capita em torno de $500 \mathrm{~kg} /($ hab. ano). O objetivo desse trabalho foi analisar a viabilidade técnica da utilização de agregados produzidos pela britagem de RCD em substituição aos materiais convencionais (areia, seixo, pedra britada e pó de pedra) na produção de blocos vazados de concreto simples para alvenaria de vedação. $O$ agregado reciclado foi caracterizado e, a partir de um traço padrão utilizado por uma empresa de pré-moldados, foram produzidos cinco novos traços de concreto em que se variou a relação entre os agregados naturais (areia artificial e areia lavada) e os agregados de RCD. Os blocos produzidos foram levados à ruptura aos 28 dias, tendo apresentado valores de resistência característica à compressão entre 2,5 MPa (com adição de areia e sem RCD) e 4,3 MPa (com RCD e sem a adição de areia), superiores ao estabelecido em norma. Conclui-se que a utilização de agregados reciclados de RCD é uma alternativa viável para substituir a brita convencional na produção de blocos vazados de vedação, contribuindo para minimizar o passivo ambiental, dando um destino adequado para os RCD e, principalmente, reduzindo a extração de agregados naturais.

ABSTRACT: In Brazil, construction and demolition waste (CDW) reach up to $60 \%$ of the total mass of solid waste (MSW) produced, with per capita generation of approximately $500 \mathrm{~kg}$ /(inhabitant.year). The objective of this paper is to analyze the technical feasibility of using recycled CDW aggregates replacing the conventional materials (sand, pebble, crushed stone and stone dust) in the production of concrete sealing blocks. The recycled aggregate was characterized and, from a trace pattern used by the partner company five new concrete mixtures were produced considering different ratios between natural aggregates (sand) and recycled CDW. The blocks produced were tested and brought to rupture after 28 days. Compression characteristic values of $2.5 \mathrm{MPa}$ (with sand and without recycled CDW aggregates) and 4.3 $\mathrm{MPa}$ (with recycled CDW aggregates and without sand) were observed. These values are above the minimum value set in Brazilian standards. The results lead to the conclusion that recycled RCD aggregates are an alternative to replace conventional gravel in the production of concrete sealing blocks, helping to minimize environmental liabilities, giving a suitable destination to the residues and, especially, reducing the extraction of natural aggregates.

\footnotetext{
* Contato com os autores:

${ }^{1}$ e-mail: leonardo.mesquita@ufv.br ( L. C. Mesquita )

Engenheiro Civil, Mestrando em Estruturas pela Universidade Federal de Viçosa (UFV).

2 e-mail : iazevedo@ufv.br ( I. C. A. D. Azevedo )

Engenheira Civil, Doutora em Engenharia Civil, Professora Titular da Universidade Federal de Viçosa (UFV).

3 e-mail: eduardo.candido@ufv.br ( E. S. Cândido )

Engenheiro Civil, Mestrando em Geotecnia pela Universidade Federal de Viçosa (UFV).

${ }^{4}$ e-mail: gabriel.cathoud@ufv.br ( G. A. Cathoud )

Estudante de graduação em Engenheira Civil pela Universidade Federal de Viçosa (UFV).
} 


\section{INTRODUÇÃO}

A indústria da construção civil, reconhecida como uma das mais importantes atividades para o desenvolvimento econômico e social se mostra, ainda, como geradora de impactos ambientais negativos no que se refere ao consumo de recursos naturais, à modificação da paisagem e geração de resíduos sólidos por novas obras (Pinto, 2005).

Segundo Boscov (2008), tendo por base dados de diversos países, os resíduos de construção e demolição (RCD) representam de 13 a $67 \%$ dos resíduos sólidos urbanos (RSU), haja vista que a geração per capita no mundo varia de 130 a $3.000 \mathrm{~kg} / \mathrm{hab}$. ano. No Brasil, essa parcela chega a atingir 60\% da massa total de RSU (Pinto, 2009), com geração per capita em torno de $500 \mathrm{~kg} / \mathrm{hab}$. ano.

Do ponto de vista ambiental, os principais problemas dos RCD são os grandes volumes gerados e a disposição irregular. $O$ descarte de forma inadequada pode promover a poluição dos mananciais, o assoreamento de rios e córregos, a contaminação do solo, deslizamentos, obstrução dos sistemas de drenagem e inundações, acabando, inclusive, por onerar as administrações municipais que têm que se responsabilizar pela remoção e disposição desses resíduos (Azevedo et al., 2006; Boscov, 2008). É necessário, portanto, adotar medidas que venham a disciplinar essas ações, como a seleção e implantação de áreas localizadas em pontos estratégicos, próximas aos pontos de geração desses resíduos, com a finalidade de receber, reaproveitar e reciclar esse material.

A reciclagem na construção civil pode gerar muitos benefícios, com reflexo direto na redução no consumo de recursos naturais não renováveis. Alternativas sustentáveis têm sido avaliadas em relação à utilização dos resíduos de construção e demolição reciclados como agregados em obras de pavimentação, na produção de argamassas, blocos e artefatos de concreto, em sistemas de drenagem e muros de peso em obras de contenção, entre outros.

\section{OBJETIVO}

Esse trabalho tem como objetivo avaliar a possibilidade de utilização de agregados reciclados de resíduos de construção e demolição em blocos vazados para alvenaria, tendo em vista sua resistência e absorção.

O uso desses resíduos na construção civil, entretanto, deve ser precedido de um estudo criterioso em relação às suas características, propriedades físicas, estanqueidade, deformabilidade e resistência, entre outras, para garantir o sucesso destes produtos no mercado. É nesse escopo que o presente trabalho se enquadra.

\section{REVISÃO BIBLIOGRÁFICA}

A forma mais difundida de tratamento dos RCD consiste na segregação da fração mineral, que é triturada até a granulometria desejada e utilizada na própria indústria da construção civil.

Uma das alternativas é o uso do agregado miúdo reciclado de RCD, em substituição ao agregado miúdo natural, pó-de-pedra, em estacas de compactação para melhoramento de solos. De acordo com Gusmão (2005), a técnica de estacas de compactação vem sendo utilizada com sucesso na cidade de Recife, PE, desde a década de 70.

Outra possibilidade é o aproveitamento dos resíduos de concreto na confecção de tijolos prensados de solo-cimento. $\mathrm{O}$ uso do solo-cimento na construção de habitações populares permite economia razoável, com redução de custos que pode atingir $40 \%$. Contribui para isso o baixo custo do solo, que é o material usado em maior quantidade, além de menores custos com transporte e energia, existindo ainda a possibilidade de redução de custos com mão-deobra, pois o processo não requer, em grande número, profissionais especializados em construção. A ideia de misturar resíduos de construção na fabricação de tijolos de solo-cimento surgiu em função da possibilidade de melhorar suas 
características mecânicas, uma vez que as características físicas dos resíduos de argamassa e concreto se assemelham às dos pedregulhos. Souza et al. (2007), avaliaram a possibilidade de aproveitamento dos resíduos de concreto na confecção de tijolos prensados de solo-cimento. Foram realizados ensaios de caracterização do solo utilizado, das composições desse solo com resíduos de concreto e das misturas de solo-cimento produzidas com essa composição, em diferentes porcentagens. Verificou-se que a adição dos resíduos proporcionou melhoria nas propriedades mecânicas do solo-cimento, favorecendo a redução do consumo de cimento e a obtenção de tijolos de melhor qualidade.

Estudos desenvolvidos por Carneiro (2005) comprovam a viabilidade da utilização de agregados reciclados de RCD na produção de blocos para alvenaria sem função estrutural. Nos testes realizados, tanto os blocos produzidos com $30 \%$ de substituição do agregado natural pelo agregado reciclado de $R C D$, quanto aqueles com $60 \%$ de substituição, apresentaram resistência à compressão simples superior ao estabelecido por norma (2,5 MPa)

Paula (2010) analisou a viabilidade de confecção de blocos com uso de agregados miúdos reciclados para uso em alvenaria de vedação, para um traço padrão cimento:agregado miúdo de 1:6. Os resultados indicaram que a substituição de 25 , 50, 75 e $100 \%$ da areia natural por agregados miúdos reciclados não afetou significativamente as propriedades mecânicas dos blocos cujos valores de resistência à compressão foram de 3,67 $\mathrm{MPa}$, 2,63 MPa, 2,44 MPa e 2,03 MPa, respectivamente.

Em obras de pavimentação, um bom exemplo é o trabalho realizado nas vias internas do campus da USP na Zona Leste de São Paulo. Todo o sistema viário, com mais de $2 \mathrm{~km}$ de extensão, foi pavimentado com camadas de agregado reciclado de entulho de obra e revestido com asfalto borracha, tendo sido denominado "pavimento ecológico". Nessa obra, para maior controle de várias propriedades que permitissem melhor entendimento desse material, foram realizados ensaios de medida de deformabilidade no campo que resultaram na conclusão de que os agregados reciclados mostram-se muito similares à brita graduada simples, aconselhando-se seu uso em camadas de subleito ou como sub-base (BERNUCCI, et al., 2009).

Nesse contexto, novos estudos de reciclagem do $\mathrm{RCD}$, além de reduzir a destinação irregular desses resíduos, evitando a poluição do meio natural, também poderão trazer razoável economia para as obras de engenharia.

\section{MATERIAL E MÉTODO}

\subsection{MATERIAIS}

\subsubsection{Agregados de RCD}

Os resíduos de construção e demolição foram coletados aleatoriamente de caçambas espalhadas na região de Muriaé, MG, que apresentavam em sua composição parcelas de material cinza (argamassas e concretos) e vermelho (cerâmicas, telhas e tijolos), além de restos de tinta, solventes, pregos e outros, que foram descartados. Desses resíduos, foram separadas amostras para caracterização física e o restante foi encaminhado a uma empresa de pré-moldados, localizada no mesmo município de coleta dos resíduos, onde foram transformados em agregados (Figura 1) por meio de seu processamento em britador de mandíbula.

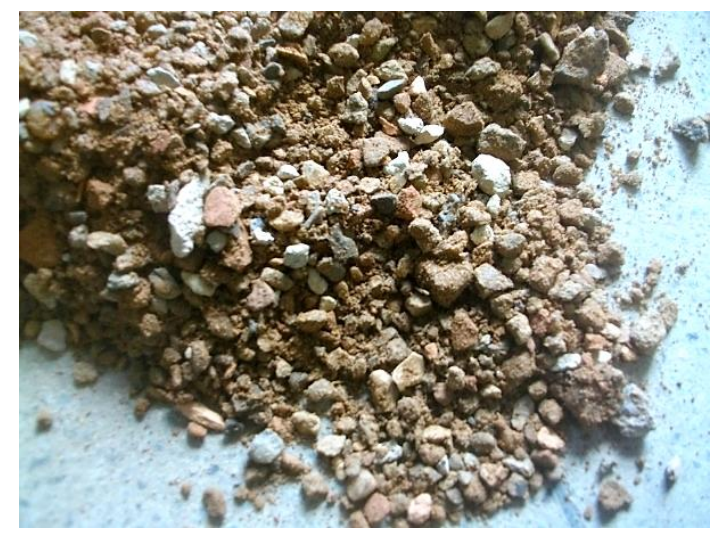

FIGURA 1. Agregado produzido por meio de britagem de RCD. Fonte: Os autores.

\subsubsection{Agregados naturais}

Na confecção dos blocos, foram utilizados como agregados naturais o pó de pedra da pedreira 
São Geraldo de Muriaé, MG, e a areia grossa do Areal Titonelli de Laranjal, MG.

\subsubsection{Aglomerante}

O aglomerante utilizado foi o Cimento Portland Maxx Concreto CPV-ARI-RS, fabricado pela Indústria Lafarge do Brasil S/A, localizada na cidade de Cantagalo, RJ, cujas características químicas e físicas estão em conformidade com a NBR 11.578 (ABNT, 2004).

\subsection{MÉTODO}

$\mathrm{Na}$ Tabela 1 listam-se as normas da Associação Brasileira de Normas Técnicas (ABNT) utilizadas na caracterização dos agregados de RCD.

\subsubsection{Dosagem do concreto}

A partir de um traço padrão, utilizado pela empresa de pré-moldados parceira, foram produzidos cinco novos traços em que se variou a relação entre os agregados naturais (areia artificial e areia lavada) e os agregados de RCD.

Os traços foram dosados em massa e a água de amassamento foi acrescentada empiricamente, de forma a se obter uma consistência adequada para o processo de prensagem. Na Tabela 2, apresentam-se os seis traços de concreto ensaiados.

TABELA 1: Normas da ABNT utilizadas na caracterização do agregado de RCD.

\begin{tabular}{cc} 
Ensaio & Norma Brasileira utilizada \\
\hline Caracterização Granulométrica & NBR 7211/2009 \\
NBR NM 248/2003
\end{tabular}

\begin{tabular}{cccccc}
\hline \multicolumn{7}{c}{ TABELA 2: Composição dos traços em massa (kg). } \\
\hline & Cimento & Água & Areia Artificial & Areia Lavada & RCD \\
\hline TRAÇO 1 & 20,0 & 25,0 & 180,8 & 172,8 & 84,2 \\
\hline TRAÇO 2 & 20,0 & 22,0 & 90,4 & 172,8 & 168,4 \\
\hline TRAÇO 3 & 20,0 & 22,0 & 90,4 & 86,4 & 252,6 \\
\hline TRAÇO 4 & 20,0 & 18,0 & - & 86,4 & 336,8 \\
\hline TRAÇO 5 & 20,0 & 16,0 & - & - & 421,0 \\
\hline TRAÇO 6 & 20,0 & 25,0 & 271,2 & 172,8 & - \\
\hline
\end{tabular}




\subsubsection{Confecção e produção dos blocos de vedação}

Os blocos de vedação em concreto, com largura nominal de $15 \mathrm{~cm}$, tinham as seguintes dimensões: $14 \mathrm{~cm}$ de largura x $19 \mathrm{~cm}$ de altura x 39 $\mathrm{cm}$ de comprimento, de acordo com a NBR 6.136 (ABNT, 2006).

Os materiais de cada um dos seis diferentes traços de concreto, cinco com agregado de RCD e um padrão, foram misturados em um misturador e prensados em uma vibro-prensa semiautomática.

\subsubsection{Processo de cura das amostras}

A cura dos blocos, para os seis traços de concreto, ocorreu ao ar livre, com proteção contra o vento e a chuva, e com irrigações periódicas de suas superfícies, nas primeiras 24 horas. Posteriormente, os blocos foram deixados em um pátio externo da empresa por 14 dias, para a conclusão do processo.

\subsubsection{Resistência à compressão}

O ensaio de resistência à compressão foi realizado em conformidade com a NBR 12.118 (ABNT, 2011), consistindo nas etapas de regularização das faces de trabalho com pastas ou argamassas, na verificação da umidade relativa dos blocos e na execução do ensaio de compressão propriamente dito.

4.2.4.1. Regularização das faces de trabalho com pastas ou argamassas

Os blocos que constituíram os corpos de prova neste ensaio foram definidos de acordo com a NBR 6.136 (ABNT, 2006).

A utilização de uma argamassa capaz de resistir às tensões do ensaio foi colocada sobre o molde de capeamento (Figura 2), cuja superfície foi previamente untada com leve camada de óleo e não se afastou do plano mais do que $8 \times 10^{-2} \mathrm{~mm}$ para cada $4 \times 10^{2} \mathrm{~mm}$. Em seguida, comprimiu-se a superfície do corpo de prova a ser capeada de encontro à argamassa, tendo-se tido o cuidado de manter as faces laterais do bloco perpendiculares à referida superfície, com tolerância máxima de $\pm 5^{\circ}$.
Finalmente, verificou-se se o capeamento se apresentava plano e uniforme e se sua espessura média não era superior a $3 \mathrm{~mm}$.

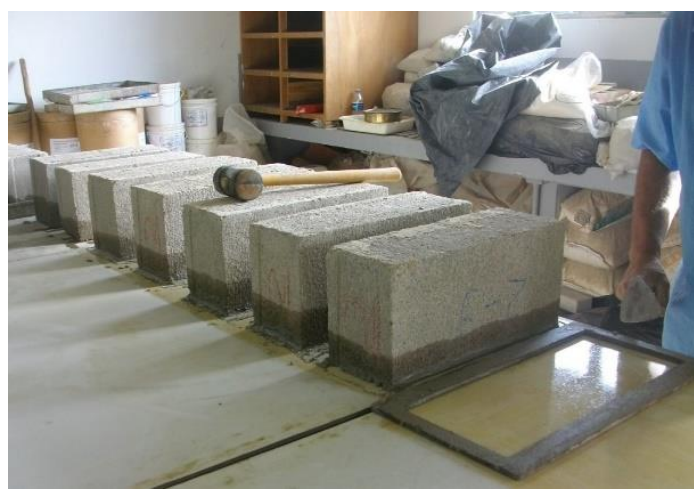

Figura 2. Processo de regularização das faces. Fonte: Os autores.

4.2.4.2. Verificação da umidade relativa dos blocos

No momento da realização do ensaio de compressão, o teor de umidade relativa média deve atender à condição de (35 \pm 10$) \%$, e deve ser determinado em três blocos que não tenham sido ensaiados à compressão. O resultado final é a média aritmética dos resultados individuais, em que a umidade relativa é determinada por meio da Equação 1.

$$
\mathrm{U}_{\mathrm{r}}=\frac{\mathrm{m}-\mathrm{m}_{1}}{\mathrm{~m}_{2}-\mathrm{m}_{1}} \cdot 100
$$

Em que:

$\mathbf{U}_{\mathrm{r}}=$ Umidade relativa do bloco (\%);

$\mathbf{m}=$ massa do corpo de prova recebido no laboratório $(\mathrm{kg})$;

$\mathbf{m}_{1}=$ massa do corpo de prova seco em estufa $(\mathrm{kg})$; $\mathbf{m}_{\mathbf{2}}=$ massa do corpo de prova na condição saturada (kg).

\subsubsection{Ensaio de compressão}

Os blocos foram ensaiados em uma máquina de ensaio universal da classe I (Figura 3), em conformidade com os requisitos da NBR NM ISO 7500-1 (ABNT, 2004), equipada com dois pratos de aço, sendo um deles articulado, atuando na face superior do corpo de prova e capaz de aplicar uma carga na direção do esforço que o bloco deve suportar durante o seu emprego.

Durante o carregamento, os dispositivos de comando da prensa foram controlados de forma que a tensão aplicada, calculada em relação à área bruta, se elevasse progressivamente e sem choques à razão de $(0,25 \pm 0,05) \mathrm{MPa} / \mathrm{s}$. 


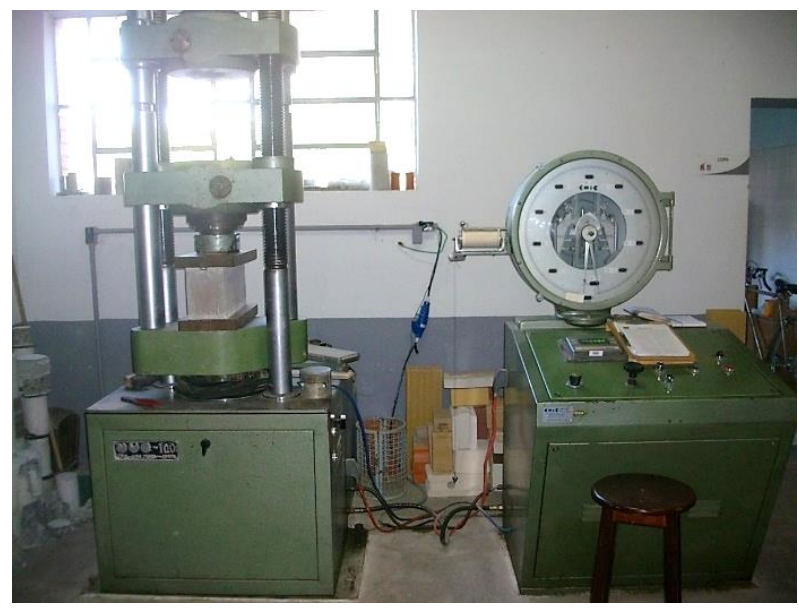

FIGURA 3. Equipamento utilizado para o ensaio de compressão.

Fonte: Os autores.

\subsubsection{Cálculo da resistência característica estimada} (f $f_{\text {bkf est }}$ )

Como não se conhece o desvio padrão de fábrica, deve-se calcular a resistência característica de cada lote, de acordo com o procedimento descrito na NBR 6136 (ABNT, 2006). O valor da resistência característica estimada ( $f_{b k}$ est) é determinado por meio da Equação 2.

$$
f_{\text {bkest }}=2\left[\frac{f_{b(1)}+f_{b(2)}+\cdots+f_{b(i-1)}}{i-1}\right]-f_{b i} \quad \text { Eq.[2] }
$$

\section{Em que:}

$i=n / 2$, se $n$ for par; $\mathbf{i}=(\mathrm{n}-1) / 2$, se $\mathrm{n}$ for ímpar;

$f_{b k}$ est $=$ resistência característica estimada da amostra (MPa);

$f_{b}(1), f_{b}(2), \ldots, f_{b}(i-1)=$ valores de resistência à compressão individual dos corpos-de-prova da amostra, ordenados em ordem crescente ( $\mathrm{MPa}$ );

$\mathbf{n}=$ número de blocos da amostra.

\subsubsection{Cálculo da resistência característica da amostra $\left(f_{b k}\right)$}

A resistência característica da amostra $\left(f_{b k}\right)$ não deve ser inferior ao valor de $f_{b k}$ est e deve ser superior a $f_{(b 1)} \cdot \psi$, em que o valor de $\psi$ é dado na Tabela 3, em função de $n$. No caso em estudo, temse $n=6$ e $\psi=0,89$.

\section{RESULTADOS E DISCUSSÃO}

\subsection{CARACTERIZAÇÃO DO AGREGADO MIÚDO UTILIZADO NA PRODUÇÃO DOS BLOCOS}

$\mathrm{Na}$ produção dos blocos, utilizou-se apenas a fração miúda do agregado de RCD, cuja granulometria está representada em azul na Figura 4. Pode-se observar que a curva granulométrica proveniente da avaliação dos RCD se apresentou em grande parte dentro dos limites estabelecidos pela NBR 7211 (ABNT, 2005) (curvas em vermelho), com apenas dois pontos projetados ligeiramente fora dos limites propostos.

\section{TABELA 3: Resistência característica dos blocos.}

\begin{tabular}{cccccccccccc} 
Número de Blocos da amostra & $\mathbf{6}$ & $\mathbf{7}$ & $\mathbf{8}$ & $\mathbf{9}$ & $\mathbf{1 0}$ & $\mathbf{1 1}$ & $\mathbf{1 2}$ & $\mathbf{1 3}$ & $\mathbf{1 4}$ & $\mathbf{1 5}$ \\
\hline $\boldsymbol{\Psi}$ & 0,89 & 0,91 & 0,93 & 0,94 & 0,96 & 0,97 & 0,98 & 0,99 & 1,00 & 1,01 \\
\hline
\end{tabular}

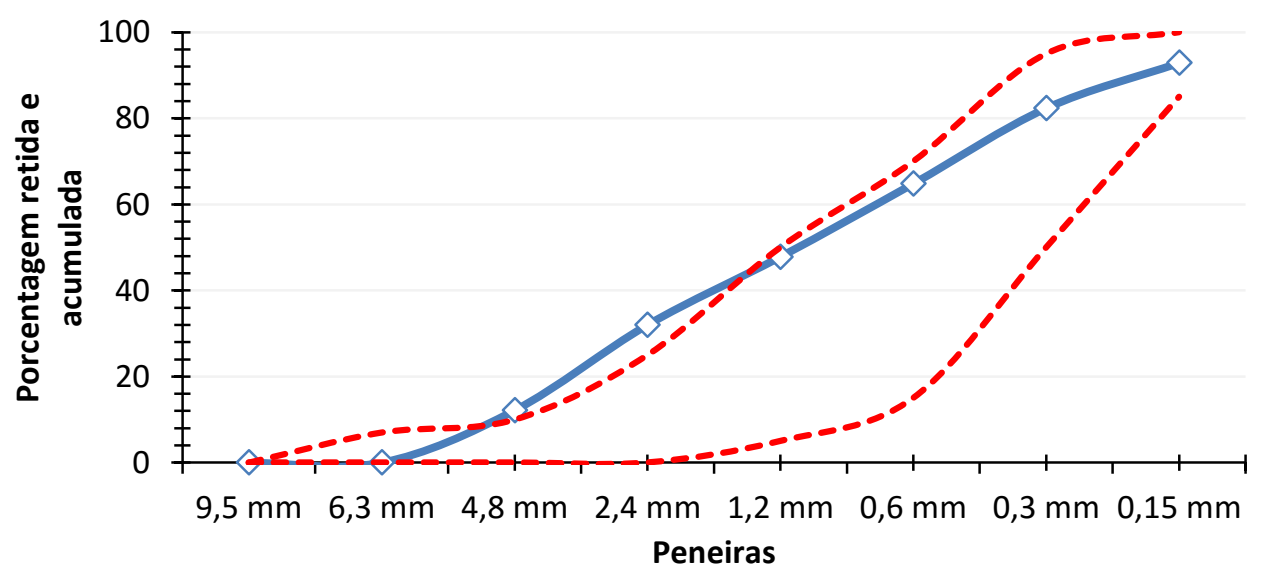

Figura 4. Curva granulométrica (azul) do agregado miúdo de RCD entre os limites propostos pela normatização.

Fonte: Os autores. 


\subsection{CARACTERIZAÇÃO DO AGREGADO DE RCD}

$\mathrm{Na}$ Tabela 4 estão apresentados os resultados obtidos da caracterização do agregado de RCD.

\subsubsection{Dimensão máxima característica e módulo de finura do agregado de RCD}

O valor encontrado para a dimensão máxima característica do agregado de RCD utilizado na confecção dos blocos foi de $12,5 \mathrm{~mm}$. Para o módulo de finura obteve-se o valor de 3,99 que, segundo Petrucci (1981), corresponde à classe de areia grossa/pedrisco.

\subsubsection{Teor de material pulverulento no agregado de RCD}

O valor encontrado para o teor de material pulverulento nos agregados de RCD foi determinado a partir de duas amostras, sendo maior do que aquele estabelecido pela norma técnica NBR 7221 (ABNT, 2005), que define em 5\% o valor máximo para agregado oriundo de pedra britada ou seixo, para uso em concretos com acabamento superficial, e em 3\% para concretos submetidos a desgaste superficial.

De acordo com a NBR NM 46 (ABNT, 2003), os resultados de duas determinações não devem divergir mais do que $0,5 \%$ para o agregado graúdo e 1,0\% para o agregado miúdo. Entretanto, por se tratar de material frágil e que se desintegra com relativa facilidade, pode-se considerar baixo 0 teor encontrado, não tendo influenciado no procedimento de confecção dos blocos.

\subsubsection{Determinação da massa específica e absorção do agregado de RCD}

Com base nos resultados apresentados na Tabela 4, verifica-se que os valores de massa específica nas condições saturada superfície seca (SSS) e aparente divergiram entre as frações miúda e graúda. Como se trata do mesmo material, os valores deveriam ser aproximadamente os mesmos. A diferença pode ser atribuída à perda de pequena parte de material mais fino do agregado graúdo ao longo do processo de caracterização, pela facilidade que tem o material de se transformar em pó. Como as massas específicas na condição SSS e aparente para a fração graúda do agregado são menores do que para a fração miúda, a absorção é consequentemente maior.

\subsubsection{Teor de impurezas orgânicas dos agregados de RCD}

Na Figura 5, apresentam-se os frascos com a solução de hidróxido de sódio a $3 \%$ colocada em contato com o agregado de RCD (à direita), e com a solução referência de ácido tânico a $2 \%$ (à esquerda). A comparação colorimétrica entre as duas soluções mostra que a solução com agregado de RCD apresentou tonalidade mais clara, indicando que o teor de material orgânico presente no agregado de RCD está dentro da faixa permitida em norma.

\begin{tabular}{|c|c|c|c|c|c|c|c|}
\hline Material & $\begin{array}{c}\text { Massa } \\
\text { Específica } \\
\text { Aparente } \\
\left(\mathrm{g} / \mathrm{cm}^{3}\right)\end{array}$ & $\begin{array}{c}\text { Massa } \\
\text { Específica } \\
\text { Seca } \\
\left(\mathrm{g} / \mathrm{cm}^{3}\right)\end{array}$ & $\begin{array}{c}\text { Massa } \\
\text { Específica } \\
\text { Saturada } \\
\text { Superfície } \\
\text { Seca }\left(\mathrm{g} / \mathrm{cm}^{3}\right) \\
\end{array}$ & $\begin{array}{c}\text { Teor de } \\
\text { material } \\
\text { pulverulento } \\
\text { (\%) }\end{array}$ & $\begin{array}{c}\text { Módulo } \\
\text { de } \\
\text { Finura }\end{array}$ & $\begin{array}{c}\text { Absorção } \\
\text { (\%) }\end{array}$ & $\begin{array}{c}\text { Diâmetro } \\
\text { Máximo } \\
\text { característico } \\
(\mathrm{mm})\end{array}$ \\
\hline $\begin{array}{l}\text { Agregado } \\
\text { de RCD }\end{array}$ & - & - & - & 5,6 & 3,99 & & 12,5 \\
\hline Fração & & & & & & & \\
\hline $\begin{array}{l}\text { Miúda de } \\
\text { RCD }\end{array}$ & 2,11 & 2,57 & 2,30 & - & - & 8,50 & - \\
\hline Fração & & & & & & & \\
\hline $\begin{array}{c}\text { Graúda de } \\
\text { RCD }\end{array}$ & 1,99 & 2,57 & 2,22 & - & - & 10,72 & - \\
\hline
\end{tabular}




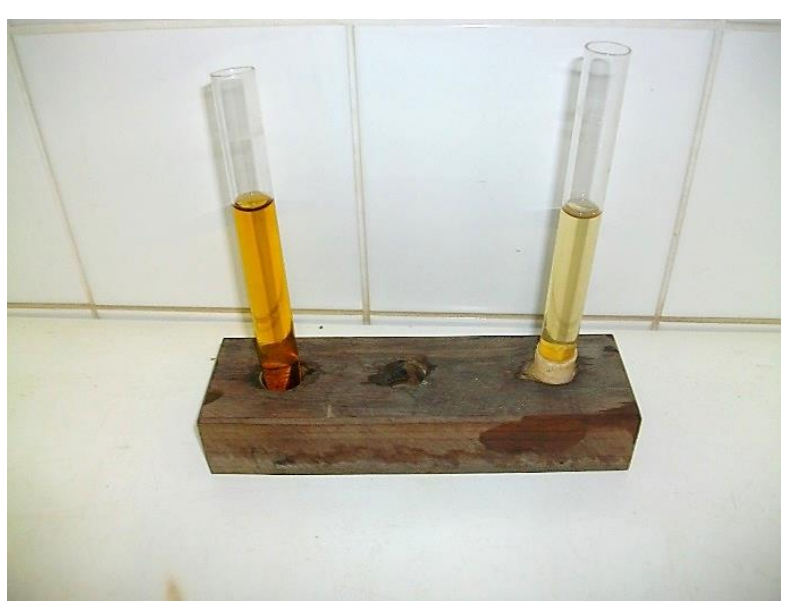

FIGURA 5. Comparação colorimétrica entre as soluções.

Fonte: Os autores.

\subsection{RESULTADOS DE ANÁLISE DIMENSIONAL DOS BLOCOS PRODUZIDOS}

Na Tabela 5, encontram-se os resultados das dimensões médias dos blocos produzidos para os traços de concreto analisados. De acordo com a norma NBR 6136 (ABNT, 2006), que estabelece as dimensões reais dos blocos vazados de concreto simples para alvenaria e sua designação, os blocos produzidos são classificados como da família M-15.

TABELA 5: Dimensões médias dos blocos produzidos.

\begin{tabular}{ccc} 
& Média & Desvio Padrão \\
\hline Largura $(\mathrm{mm})$ & 385 & 0,7 \\
\hline Altura $(\mathrm{mm})$ & 186 & 2,3 \\
\hline Comprimento $(\mathrm{mm})$ & 142 & 0,4 \\
\hline Parede longitudinal $(\mathrm{mm})$ & 26 & 0,3 \\
\hline Parede transversal $(\mathrm{mm})$ & 22 & 0,5 \\
\hline Menor dimensão do furo $(\mathrm{mm})$ & 81 & 0,4 \\
\hline
\end{tabular}

\subsection{RESISTÊNCIA A COMPRESSÃO INDIVIDUAL E RESISTÊNCIA CARACTERÍSTICA À COMPRESSÃO DOS LOTES PRODUZIDOS}

$\mathrm{Na}$ Figura 6 são apresentados os resultados médios dos ensaios de resistência à compressão, para cada traço de concreto. Para os lotes ensaiados, os valores de resistência característica dos blocos $\left(f_{b k}\right)$ encontram-se na Tabela 6 e na Figura 7.

Os valores de resistência característica se mostraram superiores ao mínimo definido na NBR 6.136 (ABNT, 2006), para a classe D ( $\geq 2,0$ $\mathrm{MPa}$ ). Valores menores de resistência à compressão eram esperados para os blocos produzidos com maiores percentuais de agregados de RCD. Entretanto, devido a sua menor relação água/cimento, verificou-se maior resistência característica para estes blocos. Diferentemente, os ensaios conduzidos por Paula (2010) mostraram que ao se adicionar ao concreto um percentual de agregados reciclados maior do que 50\%, a resistência diminui significativamente, o que poderia ser justificado pelo fato de que 35,5\% da fração pétrea do entulho eram formadas por material cerâmico e, por seu maior teor de material pulverulento.

Salienta-se a dificuldade em estabelecer um valor limite para a relação água/cimento que leve à máxima resistência, e para qual a consistência seja adequada para o processo de prensagem dos blocos. De acordo com Paula (2010), misturas de concretos com agregados reciclados necessitam de mais água que os concretos convencionais em virtude da alta taxa de absorção apresentada pelo material reciclado.

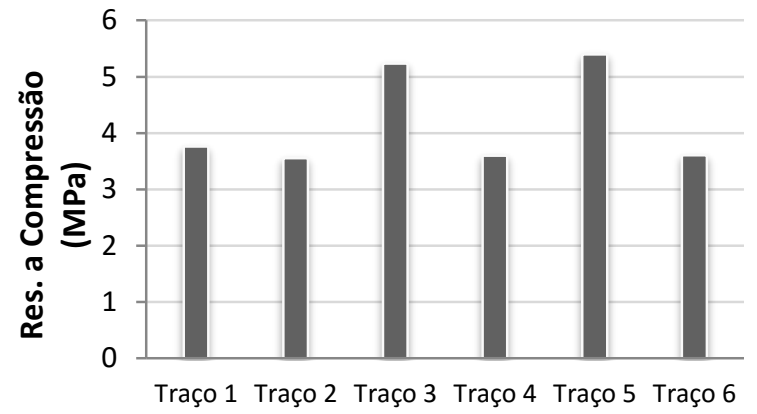

Figura 6. Resultados médios dos ensaios de resistência à compressão. Fonte: Os autores.

TABELA 6: Resistência característica dos blocos.

\begin{tabular}{ccccccc} 
Resistência (MPa) & Traço 1 & Traço 2 & Traço 3 & Traço 4 & Traço 5 & Traço 6 \\
\hline $\mathbf{F}_{\text {bk est }}$ & 3,1 & 2,9 & 4,2 & 2,8 & 4,8 & 2,5 \\
\hline $\mathbf{f}_{(\mathbf{b} 1) \cdot \boldsymbol{\Psi}}$ & 2,9 & 2,9 & 3,6 & 2,8 & 4,3 & 2,5 \\
\hline $\mathbf{f b k}_{\mathrm{b}}$ & 2,9 & 2,9 & 3,6 & 2,8 & 4,3 & 2,5
\end{tabular}




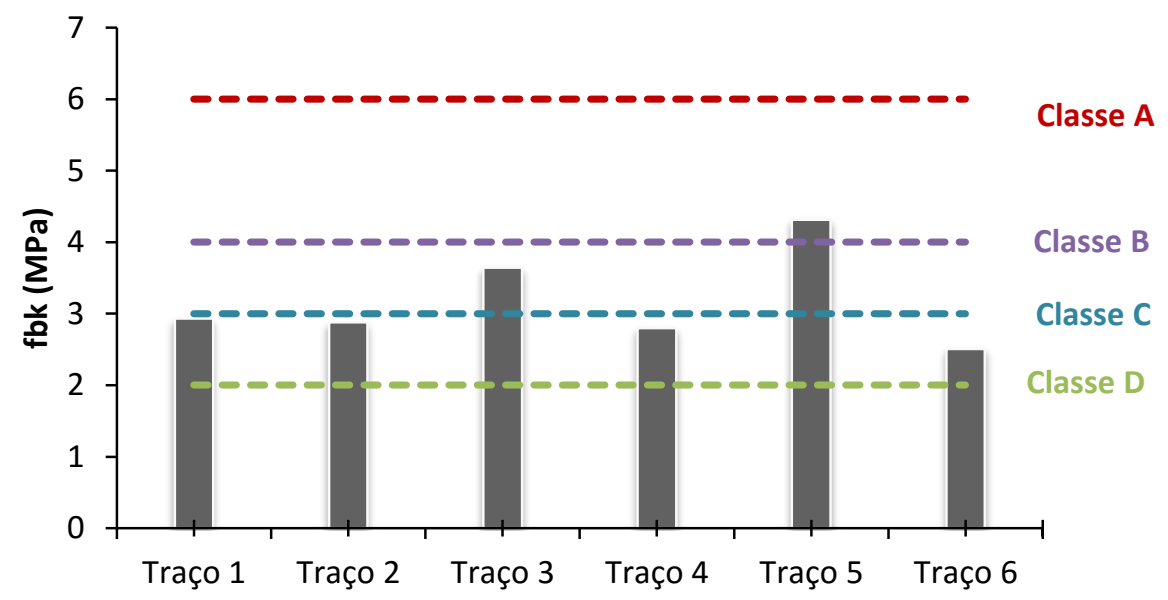

FIGURA 7. Resultados de resistência característica dos blocos produzidos e valores mínimos definidos em norma para cada classe.

Fonte: Os autores.

\section{CONCLUSÕES}

Tendo em vista os conceitos de sustentabilidade, pesquisas têm sido direcionadas no sentido de buscar alternativas para controlar ou minorar os danos provocados pelo consumo exacerbado de matéria prima e pelos grandes volumes de resíduos gerados nos processos de produção. A utilização de resíduos de construção e demolição reciclados tem se mostrado uma atividade bastante promissora em pavimentação e em aplicações como a incorporação deste material ao concreto, na produção de blocos de alvenaria, por exemplo. No sentido de ampliar ainda mais o conhecimento acerca do comportamento destes resíduos em concreto, analisou-se a viabilidade técnica da utilização de agregados produzidos pela britagem de RCD, em substituição aos materiais convencionais, na produção de blocos vazados de concreto simples para alvenaria de vedação. $\mathrm{O}$ agregado reciclado foi caracterizado e, a partir de um traço padrão utilizado por uma empresa de premoldados foram produzidos cinco novos traços de concreto em que se variou a relação entre os agregados naturais (areia artificial e areia lavada) e os agregados de RCD. Considerando-se os aspectos relativos à resistência à compressão, os resultados encontrados a partir de ensaios normatizados atestam a viabilidade técnica da utilização de agregados reciclados de resíduos oriundos de construções e demolições como produto alternativo à brita convencional na produção de blocos vazados de concreto simples para alvenaria de vedação.

A resistência mecânica à compressão, aos vinte e oito dias, para os blocos produzidos com diferentes traços, apresentaram resistência característica superior a 2,0 MPa, e absorção de água inferior a $16 \%$, resultados em conformidade com o que estabelece a NBR 6136 (ABNT, 2006).

Ressalta-se que a utilização racional e sustentável de materiais alternativos como os RCD é uma forma adequada de minimizar o passivo ambiental gerado por esse tipo de resíduo e, principalmente, de reduzir o consumo de recursos naturais não renováveis. Recomenda-se, entretanto, que novas pesquisas sejam realizadas para avaliar aspectos não contemplados neste trabalho, como a interação com outros componentes das edificações, aderência, revestimento e absorção de água e a durabilidade das obras.

\section{AGRADECIMENTOS}

Ao CNPq pela bolsa de iniciação científica concedida ao primeiro autor, à empresa Premoldados Muriaé Ltda. e à Universidade Federal de Viçosa pela estrutura disponível para a realização dos trabalhos e à FAPEMIG, pelos recursos concedidos. 


\section{REFERÊNCIAS BIBLIOGRÁFICAS}

ANGULO, S.C. Caracterização de Agregados de Resíduos de Construção e Demolição Reciclados e a Influência de suas Características no Comportamento Mecânico dos Concretos. Tese de doutorado. Escola Politécnica, Universidade de São Paulo. São Paulo, SP, 2005, $149 \mathrm{p}$.

ASSOCIAÇÃO BRASILEIRA DE NORMAS TÉCNICAS, NBR 12118: Blocos vazados de concreto simples para alvenaria - Métodos de ensaio. Rio de Janeiro, 2011.

NBR 11578: Cimento Portland Composto. Rio de Janeiro, 1991.

NBR 6136: Blocos vazados de concreto simples para alvenaria - Requisitos. Rio de Janeiro, 2006.

NBR 7211: Agregados para concretos Especificação. Rio de Janeiro, 2005.

NBR 7218: Agregado - Determinação teor de argila em terrões e materiais friáveis. Rio de Janeiro, 1987.

NBR NM 248: Agregado - Determinação da composição granulométrica. Rio de Janeiro, 2003.

NBR NM 26: Agregados - Amostragem. Rio de Janeiro, 2001.

NBR NM 27: Agregados - Redução da amostra de campo para ensaios de laboratório. Rio de Janeiro, 2001.

NBR NM 30: Agregado miúdo - Determinação da absorção de água. Rio de Janeiro, 2001.

NBR NM 46: Agregado - Determinação do material fino que passa através da peneira $75 \mu \mathrm{m}$, por lavagem . Rio de Janeiro, 2003.

NBR NM 49: Agregado miúdo - Determinação de impurezas orgânicas. Rio de Janeiro, 2001.

NBR NM 52: Agregado miúdo - Determinação da massa específica e massa específica aparente. Rio de Janeiro, 2003.

NBR NM 53: Agregado graúdo - Determinação da massa específica, massa específica aparente e absorção de água. Rio de Janeiro, 2003.

NBR NM ISO 3310-1: Peneiras de ensaio Requisitos técnicos e verificação. Parte 1 - Peneiras de ensaio com tela de tecido metálico. Rio de Janeiro, 1997.

NBR NM ISO 7500-1: Materiais metálicos Calibração de máquinas de ensaio estático uniaxial. Parte 1 - Máquinas de ensaio detração/compressão Calibração do sistema de medição da força. Rio de Janeiro, 2004.
AZEVEDO, G.O.D. et al. Resíduos da construção civil em Salvador: Os caminhos para uma gestão sustentável. Engenharia Sanitária e Ambiental. V. 11 - no 1. - Rio de Janeiro/RJ: ABES, 2006. 65-72 p.

BERNUCCI, L.B. et al. Pavimento ecológico. Revista Téchne. 2009. Disponível em: http://www.revistatechne.com.br/engenhariacivil/126/imprime62005.asp. Acessado em: Jul/2009.

BOSCOV, M.E. Geotecnia Ambiental. Editora Oficina de Textos, São Paulo, SP, 2008, 248 p.

CARNEIRO, F.P. Diagnóstico e ações da atual situação dos resíduos de construção e demolição na cidade do Recife. Dissertação. Engenharia Urbana. Universidade Federal da Paraíba, João Pessoa, 2005. 131 p.

CONSELHO NACIONAL DO MEIO AMBIENTE - CONAMA. Resolução 307, de 05 de julho de 2002. Dispõe sobre a gestão dos resíduos da construção civil. Disponível em http://www.mma.gov.br/port/conama/res/res02/res30 702.html. Acessado em: Jul/2009.

CONSELHO NACIONAL DO MEIO AMBIENTE - CONAMA. Resolução 348, de 17 de agosto de 2004. Altera a Resolução CONAMA № 307, de 5 de julho de 2002, incluindo o amianto na classe de resíduos perigosos. Disponível

em: http://www.mma.gov.br/port/conama/res/res04/res34 804.xml. Acessado em: Jul/2009.

GUSMÃO, A.D. Melhoramento de Terrenos Arenosos. In: Alexandre Duarte Gusmão; Jaime de Azevedo Gusmão Filho; Joaquim Teodoro Romão de Oliveira; Gilmar de Brito Maia, (eds.). Geotecnia no Nordeste, Editora da Universidade Federal de Pernambuco, Recife, v. 1, 2005, 331-363 p.

JOHN, V. M. Reciclagem de resíduos na construção civil: Contribuição à metodologia de pesquisa e desenvolvimento. Tese (Livre Docência) - Escola Politécnica, Universidade de São Paulo. São Paulo, SP, 2000, 113 p.

LIMA, G. L. et al. Programa de gestão diferenciada de resíduos sólidos inertes em Santo André: Estação entulho. In: Simpósio Internacional De Qualidade Ambiental - Gerenciamento de Resíduos e Certificação Ambiental, 2., Porto alegre. Anais... Porto Alegre, 1998, 413-418 p.

MEDEIROS, J.S. Alvenaria estrutural não armada de blocos de concreto: produção de componentes e parâmetros de projeto. Dissertação. Escola Politécnica, Universidade de São Paulo, São Paulo, SP, 1993, 449 p.

PAULA, P.R.F. Utilização dos resíduos da construção civil na produção de blocos de argamassa sem função estrutural. Dissertação. Tecnologia das Construções. Universidade Católica de Pernambuco, Recife, PE, 2010. $131 \mathrm{p}$. 
PETRUCCI, E. G. R. Concreto de cimento Portland. 8a ed.. Porto Alegre - Rio de Janeiro, RJ, Editora Globo, 1981.

PINTO, T. P. Resíduos da Construção Civil: Soluções Sustentáveis para um grave problema urbano - Novas Normas, Legislação e soluções. São Paulo: Informações e Técnicas. 2005.

PINTO, T.P. Gerenciamento de resíduos. Revista Construção Mercado. São Paulo, n.91, fev. 2009, 16-17 p.

PINTO, T.P. Gestão Ambiental dos Resíduos da Construção Civil: A experiência do SINDUSCON-SP. São Paulo, 2005, 48p.

PINTO, T.P. Resíduos da construção civil - Nova legislação permite rápido avanço para normas técnicas e novas soluções. 2009. Disponível em: www.ietsp.com.br. Acessado: julho/2009.

SOUZA, J. G. G. Contribuição ao estudo da relação entre propriedades e proporcionamento de blocos de concreto - Aplicação ao uso de entulho como agregado reciclado. Tese (Mestrado em Estruturas) - Faculdade de Tecnologia, Universidade de Brasília. Distrito Federal, DF, 2001. 120p.

SOUZA, I.B.; SEGANTINI, A.A.S.; PEREIRA, J.A.. Tijolos prensados de solo-cimento confeccionados com resíduos de concreto. Revista Brasileira de Engenharia Agrícola e Ambiental. Campina Grande, PB, V.12, n.2, 2007, 205-212 p. 